\title{
Rehabilitation of Post-COVID GBS Patient: Acute Care and Functional Recovery
}

ISSN: 2576-9200

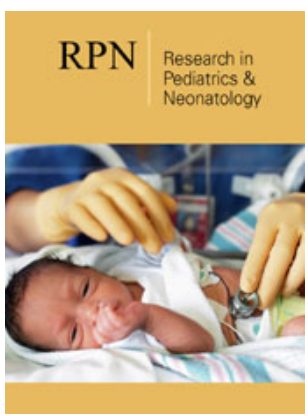

*Corresponding author: Ramanandi $\mathrm{VH}$, Assistant Professor, SPB Physiotherapy College, Surat, Gujarat, India

Submission: 䤈 November 03, 2020

Published: 眥 December 02, 2020

Volume 5 - Issue 2

How to cite this article: Ramanandi $\mathrm{VH}$ Rehabilitation of Post-COVID GBS Patient: Acute Care and Functional Recovery. Research in Pediatrics \& Neonatology. 5(2). RPN. 000607. 2020.

DOI: $10.31031 / R P N .2020 .05 .000607$

Copyright $\odot$ Ramanandi VH. This article is distributed under the terms of the Creative Commons Attribution 4.0 International License, which permits unrestricted use and redistribution provided that the original author and source are credited.

\section{Ramanandi $\mathrm{VH}^{*}$}

Assistant Professor, SPB Physiotherapy College, Surat, Gujarat, India

\begin{abstract}
Guillain-Barré syndrome (GBS) is an inflammatory polyradiculoneuropathy associated with numerous viral infections. Since corona virus disease-2019 (COVID-19) outbreak in January 2020, several pieces of evidence suggested an association between the spectrum of GBS and severe acute respiratory syndrome coronavirus-2 (SARSCoV-2). As physiotherapy plays an important role in rehabilitation of GBS patient as well as COVID-19 cases, the rehabilitation from acute and post-acute phase up to and including functional recovery depends majorly on physiotherapy interventions. This case report discusses the medical and physiotherapy management of such patient briefly and describes the process from acute care to functional recovery.
\end{abstract}

Keywords:COVID-19; SARSCoV-2; Coronavirus; Guillain-Barré syndrome; Physiotherapy; Rehabilitation

\section{Introduction}

Severe acute respiratory syndrome coronavirus-2 (SARS-CoV-2) infection pandemic has rapidly spread around the world from Jan-2020, with more than 14,000,000 cases confirmed so far 46.4 million [1]. Although it primarily affects the respiratory system, central and peripheral neurological manifestations are also found to be associated with SARS-CoV-2 infection [2]. Several studies suggested an association between SARS-CoV-2 infection and the development of Guillain-Barré Syndrome (GBS) [3-5]. A recent pathological study on postmortem human brain tissues found that anosmia and dysgeusia, described in up to $20 \%$ of patients, are more likely due to the direct viral invasion of the olfactory nerve and bulb [6]. Also, in line with this observation, a COVID-19 patient with anosmia showed magnetic resonance imaging (MRI) abnormalities in the olfactory bulb and in the inferior frontal lobe, as a conceivable result of the direct invasion of SARS-CoV-2 through the olfactory pathway via trans-synaptic retrograde spreading [7].

Here we describe a patient with an axonal variant of GBS following COVID-19, and we report the acute and post-acute physiotherapy interventions and their effects on various functional and quality of life related outcomes in a GBS patient related to SARS-CoV-2 infection.

\section{Case Report}

A 27-year-old man developed fever (of up to $39^{\circ} \mathrm{C}$ ) which lasted for 5 days along with cough and dysgeusia with anosmia. At After the resolution of the symptoms, the patient complained of tingling and numbness in both hands after around 7 days and also in feet after 10 days. Over next 1 week, the patient developed weakness gait impairment associated with distal limb weakness and was referred to the emergency department of tertiary care private hospital. Neurological examination showed affection of strength of the extensors of hand and fingers [Medical Research Council (MRC) score: 3/5 bilaterally); the dorsi flexors of the foot and the extensors of the toes [Medical Research Council (MRC) score: 2/5 on the left side and $3 / 5$ on the right side]; ataxic gait; impaired touch and vibration sensation in the feet and ankles; absent ankle jerk, and diminished tendon reflexes in the upper and the lower limbs. The cranial nerves were not affected. Nasopharyngeal swab test for SARS-CoV-2 with real time polymerase chain reaction assay (RT-PCR) was negative while the chest radiograph showed no signs of pneumonia.

Further diagnostic workup performed 4 weeks after the neurologic onset, with nerve conduction studies showed reduced or absent compound muscle action potentials (CMAPs) and sensory nerve action (SNAPs) potentials in the lower limbs, absent F wave response in 
the lower limbs, and prolonged $\mathrm{F}$ wave response in the upper limbs. The electromyography (EMG) displayed spontaneous activity (i.e. fibrillation potentials and positive sharp waves) in the lower limb muscles (Table 1). The cerebrospinal fluid (CSF) examination showed normal values of cell count, proteins, CSF/serum albumin ratio, and absence of oligoclonal band. Serum SARS-CoV-2 IgG was detected. The laboratory investigations demonstrated high C-reactive protein $(21.9 \mathrm{mg} / \mathrm{dl})$. The serological tests for antiEBV, anti-CMV, and anti-MP IgG were positive. An intravenous immunoglobulin (IVIG) cycle at $0.4 \mathrm{~g} / \mathrm{kg} /$ day over 5 days was started, leading to a significant improvement in strength of the upper limbs but a poor benefit on the feet and gait ataxia.

Table 1: Neurophysiologic Findings.

\begin{tabular}{|c|c|c|c|c|c|c|c|}
\hline $\begin{array}{l}\text { Antidromic } \\
\text { Sensory NCS }\end{array}$ & $\begin{array}{l}\text { Latency } \\
\text { (ms) }\end{array}$ & $\begin{array}{c}\text { Amplitude } \\
(\mu V)\end{array}$ & $\begin{array}{l}\text { Velocity } \\
\text { (m/s) }\end{array}$ & Motor NCS & $\begin{array}{c}\text { Latency Prox- } \\
\text { imal/Distal } \\
\text { (ms) }\end{array}$ & $\begin{array}{c}\text { Amplitude } \\
\text { Proximal/Distal } \\
\text { (mV) }\end{array}$ & Velocity $(\mathrm{m} / \mathrm{s})$ \\
\hline $\begin{array}{c}\text { Sural: } \\
\text { Posterior ankle }\end{array}$ & $\begin{array}{l}\mathrm{R}=\mathrm{NE} \\
\mathrm{L}=\mathrm{NE}\end{array}$ & $\begin{array}{l}\mathrm{R}=\mathrm{NE} \\
\mathrm{L}=\mathrm{NE}\end{array}$ & $\begin{array}{c}\mathrm{R}=\mathrm{NE} \\
\mathrm{L}=\mathrm{N}\end{array}$ & $\begin{array}{c}\text { Tibial: } \\
\text { Medial } \\
\text { malleolus-Abductor } \\
\text { hallucis brevis; Popliteal } \\
\text { fossa- Medial malleolus }\end{array}$ & $\begin{array}{l}\mathrm{R}=\mathrm{NE} \\
\mathrm{L}=\mathrm{NE}\end{array}$ & $\begin{array}{l}\mathrm{R}=\mathrm{NE} \\
\mathrm{L}=\mathrm{NE}\end{array}$ & $\begin{array}{l}\mathrm{R}=\mathrm{NE} \\
\mathrm{L}=\mathrm{NE}\end{array}$ \\
\hline Radial: Thumb & $\begin{array}{l}\mathrm{R}=4.3 \\
\mathrm{~L}=\mathrm{NE}\end{array}$ & $\begin{array}{c}\mathrm{R}=0.11 \\
\mathrm{~L}=\mathrm{NE}\end{array}$ & $\begin{array}{l}R=31 \\
L=N E\end{array}$ & \multirow{2}{*}{$\begin{array}{l}\text { Common peroneal: } \\
\text { Ankle-Extensor } \\
\text { digitorum brevis; Below } \\
\text { fibula-Ankle }\end{array}$} & \multirow{2}{*}{$\begin{array}{c}\mathrm{R}=10.9 / 4 \\
\mathrm{~L}=\mathrm{NE}\end{array}$} & \multirow{2}{*}{$\begin{array}{c}\mathrm{R}=0.1 / 0.1 \\
\mathrm{~L}=\mathrm{NE}\end{array}$} & \multirow{2}{*}{$\begin{array}{c}\mathrm{R}=36.7 \\
\mathrm{~L}=\mathrm{NE}\end{array}$} \\
\hline $\begin{array}{l}\text { Ulnar: } \\
\text { 5th digit }\end{array}$ & $\begin{array}{l}\mathrm{R}=2.4 \\
\mathrm{~L}=2.7\end{array}$ & $\begin{array}{l}R=6.2 \\
L=1.5\end{array}$ & $\begin{array}{l}\mathrm{R}=52.2 \\
\mathrm{~L}=46.2\end{array}$ & & & & \\
\hline
\end{tabular}

Electromyography showed fibrillation potentials and positive sharp waves in the tibialis anterior and gastrocnemius medialis muscles, bilaterally. L, left; NCS, nerve conduction study; NE, not evocable; R, right.

During patients stay at the hospital physiotherapy referral was given to the in-house physiotherapist and acute care physiotherapy was initiated as soon as $3^{\text {rd }}$ day of admission. During the phase of indoor admission physiotherapy management included limb physiotherapy (i.e. passive and active-assisted); preventive management for pressure sores and tightness; and respiratory physiotherapy including positioning, breathing and chest expansion exercises, diaphragmatic breathing, respiratory muscle training etc. The patient was discharged and was referred to the physiotherapy \& rehabilitation OPD at SPB Physiotherapy College. Where the patient is currently undergoing the physiotherapy and rehabilitation for GBS associated impairments.
Physiotherapy evaluation revealed following findings: MRC score for strength of the extensors of hand and fingers 3/5 bilaterally; the dorsi flexors of the foot and the extensors of the toes $2 / 5$ on the left side and 3/5 on the right side; gait ataxia with wide base staggering gait with high-steppage pattern; impaired touch and vibration sensation in the feet and ankles; diminished tendon reflexes in the upper and the lower limbs. Quality of life, mobility and handicap were assessed using World Health Organization Quality of Life-BREF, clinical mobility scale (CMS) and environment status scale (ESS). The initial, 1 month and 2 months follow up values are given in Table-2. Figure 1 shows a timeline of the clinical milestones of the patient.

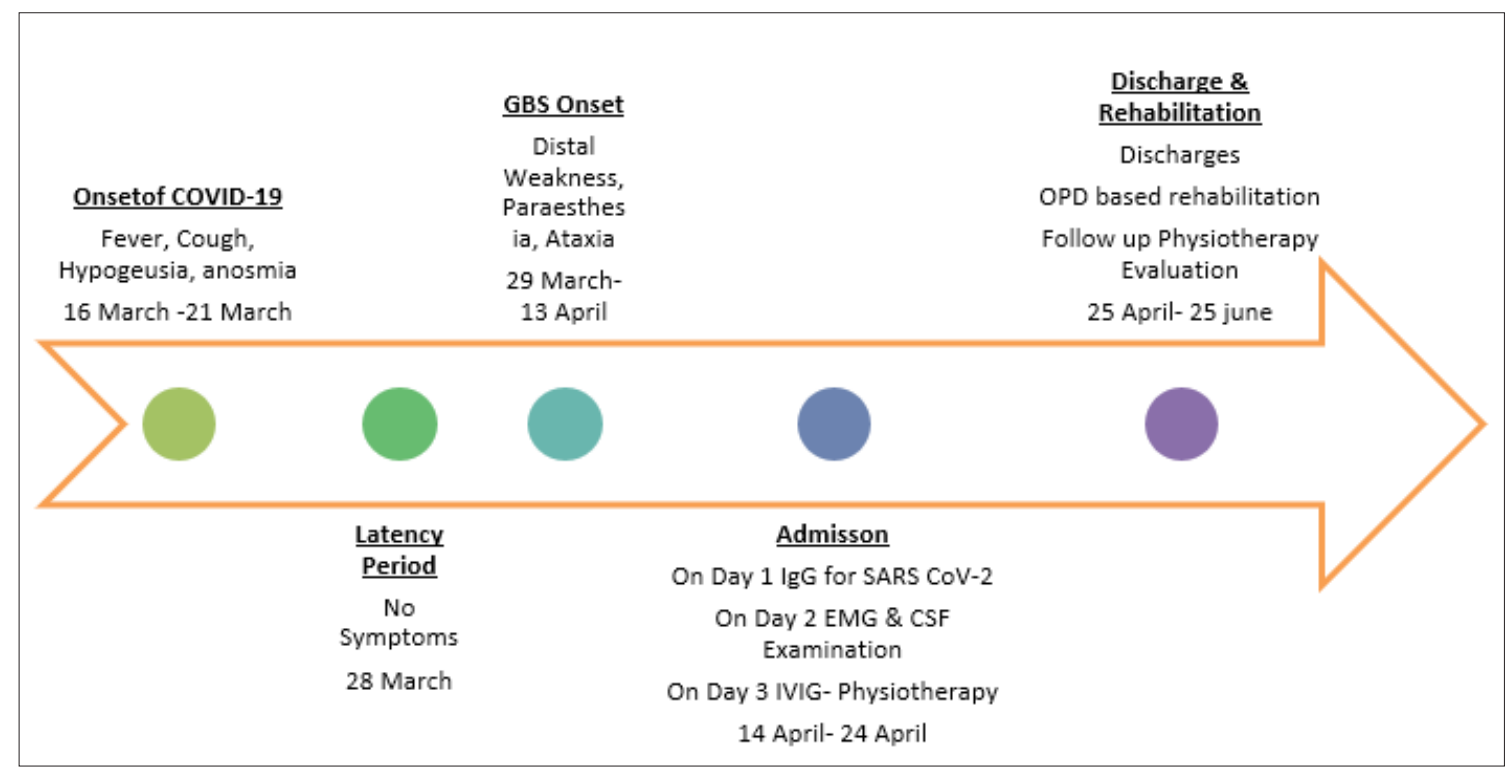

Figure 1: Timeline of clinical events, diagnostic-therapeutic approach, and clinical outcome after rehabilitation. 
Table 2: Outcome Evaluation at Initial visit, 1- month \& 2- month follow up for patient.

\begin{tabular}{|c|c|c|c|c|c|c|c|}
\hline Sr. & Aspect being Measured & Outcome Measure & $\begin{array}{c}\text { Initial } \\
\text { Value }\end{array}$ & $\begin{array}{c}\mathbf{1} \text { month } \\
\text { Follow up }\end{array}$ & $\begin{array}{c}\mathbf{2} \text { month } \\
\text { Follow up }\end{array}$ & $\begin{array}{c}\text { Highest } \\
\text { Score }\end{array}$ & Interpretation \\
\hline 1 & Mobility & Clinical Mobility Scale & 16 & 20 & 22 & 24 & Higher the score greater the mobility \\
\hline 2 & Handicap & $\begin{array}{c}\text { Environmental Status } \\
\text { Scale }\end{array}$ & 21 & 18 & 15 & 35 & Higher the score greater the handicap \\
\hline 3 & Quality of Life & WHO QoL-BREF & 62 & 77 & 81 & 100 & Higher the score better the quality of life \\
\hline
\end{tabular}

\section{Discussion}

We reported a patient showing a stepwise progression of numbness, tingling, and weakness 7-10 days after the resolution of fever, cough, anosmia and dysgeusia. The clinical features and the electrophysiological findings along with the presence of IgG to SARS-CoV-2 supported the diagnosis of post-COVID-19 GBS. Specifically, the neurophysiologic findings were consistent with an acute motor-sensory axonal GBS (AMSAN) variant, with level 2 diagnostic certainty for GBS according to the Brighton Criteria (consistent clinical features and supporting nerve conduction study, but not CSF) $[8,9]$. Active SARSCoV-2 infection was excluded by a complete recovery of the typical antecedent symptoms, absence of the viral genome in the nasopharyngeal swab, and negative chest radiography. After the $1^{\text {st }}$ reported case of GBS related to SARSCoV-2, it was suggested that axonal variant is more common rather than demyelinating variant. However, in contrast to the initial reports, the electrophysiological features in other cases did not suggest a higher prevalence of axonal variants, and demyelinating and mixed forms were more often observed [10]. The case report and review of literature by Zito A, et al. [11] contribute to raise awareness of the possible association between GBS and SARSCoV-2 infection. The underlying mechanism of injury could be an autoimmune reaction against peripheral nerve antigens, in light of the lack of a viral genome in the CSF [11].

Rehabilitation following CoV-2 infection has proven to have positive effects on the health outcomes of patients, including reduction of ICU related complications, improvement in recovery, reduce disability, facilitation of early discharge, reduced risk of re-admission etc. [12]. The WHO and the PAHO have compiled a document on the rehabilitation considerations during theCOVID-19 outbreak, and the WCPT has also compiled briefing papers in response to COVID-19. The second briefing paper specifically addresses rehabilitation and the vital role of physiotherapy $[13,14]$. Currently, there is limited evidence of the impact of rehabilitation after COVID-19. The information provided is based on evidence from countries such as China, Italy and other areas. This evidence is based on the experience and expert opinions of rehabilitation healthcare professionals from these regions. General rehabilitation considerations in the post- acute phase include respiratory rehabilitation, functional rehabilitation, early mobilisation, frequent posture changes, bed mobility, sit to stand, simple bed exercises, ADLs, neuromuscular electrical stimulation, progressive aerobic exercise, education on energy conservation and behavior modification etc. [14].

\section{Conclusion}

Our case report contribute to provide the information that can help in filling up the gap in our knowledge about the possible association of GBS with SARS-CoV-2 infection and help identify the clinical rehabilitation protocol for such patients having impairments of strength and gait due to GBS. However, the relationship between SARS-CoV-2 and GBS here also is similar to those described only in single case reports and small case series, and should be confirmed in larger observational studies. The acute and post-acute care physiotherapy and rehabilitation measures for GBS cases should also be evaluated for their effectiveness in such GBS cases on larger samples. Standard guidelines regarding use of clinical rehabilitation and outcome measures along with roles and responsibilities of rehab team member should be designed for their perusal.

\section{Ethics Statement}

Written informed consent was obtained from the patient for the publication of this case report, including any potentially identifiable images or data included in this article.

\section{Conflict of Interest}

The author declares that the research was conducted in the absence of any commercial or financial relationships that could be construed as a potential conflict of interest.

\section{Acknowledgement}

The author extends his deepest gratitude towards the patient; principal, management and staff members of SPB Physiotherapy College, Surat; and all the known and unknown authors whose works have been helpful in drafting this case report.

\section{References}

1. WHO (2020) Coronavirus disease 2019 (COVID-19).

2. Mao L, Jin H, Wang M, Hu Y, Chen S, et al. (2020) Neurologic manifestations of hospitalized patients with coronavirus disease 2019 in Wuhan, China. JAMA Neurol 77(6): 683-690.

3. Alberti P, Beretta S, Piatti M, Karantzoulis A, Piatti ML, et al. (2020) Guillain-Barré syndrome related to COVID-19 infection. Neurol Neuroimmunol Neuroinflamm 7(4): e741.

4. Bigaut K, Mallaret M, Baloglu S, Nemoz B, Morand P, et al. (2020) GuillainBarré syndrome related to SARS-CoV-2 infection. Neurol Neuroimmunol Neuroinflamm 7(5): e785. 
5. Tiet MY, AlShaikh N (2020) Guillain-Barré syndrome associated with COVID-19 infection: A case from the UK. BMJ Case Rep 13(7): 1-4.

6. Meinhardt J, Radke J, Dittmayer C, Mothes R, Franz J, et al. (2020) Olfactory transmucosal SARS-CoV-2 invasion as port of central nervous system entry in COVID-19 patients. BioRxiv.

7. Politi LS, Salsano E, Grimaldi M (2020) Magnetic resonance imaging alteration of the brain in a patient with coronavirus disease 2019 (COVID-19) and anosmia. JAMA Neurol 77(8): 1028-1029.

8. Rajabally YA, Durand MC, Mitchell J, Orlikowski D, Nicolas G (2015) Electrophysiological diagnosis of Guillain-Barré syndrome subtype: Could a single study suffice? J Neurol Neurosurg Psychiatry 86(1): 115119.

9. Fokke C, Den Berg BV, Drenthen J, Walgaard C, Van Doorn PA, et al. (2014) Diagnosis of Guillain-Barré syndrome and validation of Brighton criteria. Brain 137(Pt 1): 33-43.
10. Long QX, Liu BZ, Deng HJ, Wu GC, Deng K, et al. (2020) Antibody responses to SARS-CoV-2 in patients with COVID-19. Nat Med 26(6): 845-848.

11.Zito A, Alfonsi E, Franciotta D, Todisco M, Gastaldi M, et al. (2020) COVID-19 and Guillain-Barré Syndrome: A case report and review of literature. Front Neurol 11: 909.

12. PAHO (2020) Rehabilitation considerations during the COVID-19 outbreak-2020.

13. World Confederation for Physical Therapy (2020). WCPT response to COVID-19 briefing paper 2 rehabilitation and the vital role of physiotherapy.

14. Sheehy LM (2020) Considerations for postacute rehabilitation for survivors of COVID-19. JMIR Public Health Surveill 6(2): e19462. 